\title{
Estimativas de componentes de (co)variância para peso e escores visuais de conformação frigorífica em bovinos Nelore
}

\author{
[Variance component estimates for weight and visual scores of slaughter \\ conformation in Nellore cattle] \\ R.R. Wenceslau', V.P.S. Felipe ${ }^{2}$, B.D. Valente ${ }^{2}$, A. N. Rosa ${ }^{3}$, P.R.C. Nobre ${ }^{3}$, \\ L. Martin Nieto ${ }^{3}$, M.A. Silva ${ }^{2}$ \\ ${ }^{1}$ Aluno de pós-graduação - Escola de Veterinária - Universidade Federal de Minas Gerais - Bolsista - CAPES \\ Belo Horizonte, MG \\ ${ }^{2}$ Escola de Veterinária - Universidade Federal de Minas Gerais - Belo Horizonte, MG \\ ${ }^{3}$ EMBRAPA CNPGC/ GENEPLUS - Campo Grande - MS \\ RESUMO
}

\begin{abstract}
Estimaram-se os componentes de (co)variância e herdabilidade da conformação frigorífica à desmama (CFD), conformação frigorífica ao sobreano (CFS), peso à desmama (PD) e peso ao sobreano (PS) de animais Nelore, e as correlações genéticas entre essas características. Um modelo animal multicaracterística foi proposto para analisar 6.397 informações de peso e escores visuais de conformação frigorífica, obtidas à desmama e ao sobreano. Esse modelo incluiu os efeitos aleatórios genético aditivo direto, genético aditivo materno, ambiente permanente materno e residual, além dos efeitos fixos de grupo contemporâneo e das covariáveis idade da mãe ao parto - para peso e conformação frigorífica à desmama e ao sobreano - e idade do animal à data da avaliação - para conformação frigorífica, à desmama e ao sobreano. As herdabilidades estimadas para CFD, CFS, PD e PS foram, respectivamente, 0,13, 0,25, 0,22 e 0,29. Correlações genéticas positivas e de alta magnitude entre as características de peso e as características de avaliação visual sugerem que a seleção para uma delas pode resultar em resposta indireta na outra. A característica de conformação frigorífica pode ser selecionada em idade mais precoce em razão da correlação genética alta e positiva entre mensurações feitas nas duas idades estudadas.
\end{abstract}

Palavras-chave: bovino de corte, conformação frigorífica, correlação genética, escore visual, herdabilidade

\begin{abstract}
The aim of this study was to estimate variance components, heritability and genetic correlation for slaughter conformation at weaning (SCW), slaughter conformation at yearling age (SCY), weaning weight $(W W)$ and yearling age weight $(Y W)$ of Nellore cattle. A total of 6,397 records of all traits measured at weaning and at yearling age were used in the analysis. A multiple trait animal model which included the direct genetic additive, maternal genetic additive, maternal permanent environmental and residual random effects, as well as the fixed effect of contemporary group and the covariates age at calving (for weight and slaughter conformation at weaning and yearling age) and age at the evaluation time (slaughter conformation at weaning and yearling age) was proposed. The heritability estimates for SCW, SCY, WW and YW were, respectively, 0.13, 0.25, 0.22 and 0.29. Positive and high genetic correlations between body weight traits and visual evaluation traits suggested that direct selection for one trait results in positive indirect response in the remaining trait. Slaughter conformation trait can be selected at earlier age due to the high and positive genetic correlation between conformation scores at different age.
\end{abstract}

Keywords: beef cattle, genetic correlation, heritability, slaughter conformation, visual score

Recebido em 16 de setembro de 2010

Aceito em 12 de janeiro de 2012

E-mail: rwenceslau@hotmail.com 


\section{Wenceslau et al.}

\section{INTRODUÇÃO}

O objetivo de um programa de melhoramento genético é explorar as diferenças genéticas entre os animais para aumentar o lucro de um sistema de produção. Dessa forma, a seleção de gado de corte não deve basear-se somente no peso e no ganho de peso dos animais, uma vez que a lucratividade do sistema de produção também é função de outras características. Há necessidade, portanto, de se definirem as características que serão incluídas no índice de seleção para se obterem animais funcionais, adequados ao meio de produção, bem como economicamente eficientes (Faria et al., 2007).

Atualmente, alguns programas de melhoramento genético incorporam características de avaliação visual de carcaça no critério de seleção, como a conformação frigorífica, com o propósito de identificar animais que apresentem melhor composição de carcaça e que, portanto, poderiam ser abatidos mais precocemente. Segundo Josahkian et al. (2003), o objetivo básico das características envolvidas na avaliação visual dos diferentes tipos morfológicos é identificar aqueles animais que, nas condições viáveis de criação e em consonância com o mercado consumidor, cumpram seu objetivo eficientemente e em menos tempo. A adoção de características avaliadas por escores visuais representa vantagens para o melhoramento genético de características relacionadas à carcaça, comparada à avaliação post mortem. O tempo para se obterem resultados diminui, e os gastos com a coleta de dados são consideravelmente menores (Koury Filho, 2005).

Apesar de haver carência de pesquisas que relacionem efetivamente as características de carcaça avaliadas por escore visual in vivo com características medidas diretamente no animal post mortem, alguns autores sugerem que as avaliações visuais por escores são interessantes ferramentas a serem utilizadas na seleção de animais mais pesados e com melhor conformação morfológica, enfatizando características como volume de musculatura e precocidade de acabamento (May et al., 1992; Koury filho, 2001). Resultados de pesquisas científicas sugerem que as características de conformação, musculosidade e precocidade podem apresentar, em programas de seleção que as utilizem como critério, ganhos genéticos consideráveis, visto que as herdabilidades dessas características são de média a moderada magnitude (Cardoso et al., 2001; Van Mellis et al., 2003; Cardoso et al., 2004; Koury Filho, 2005; Kippert et al., 2006; Yokoo et al., 2009).

Dada a escassez de trabalhos científicos sobre estimativas de parâmetros genéticos da conformação frigorífica em animais da raça Nelore, a presente pesquisa foi realizada para estimar as herdabilidades $\mathrm{e}$ as correlações genéticas para características de conformação frigorífica à desmama, conformação frigorífica ao sobreano, peso à desmama e peso ao sobreano.

\section{MATERIAL E MÉTODOS}

Os dados utilizados neste trabalho são provenientes de animais da raça Nelore participantes da avaliação genética realizada pelo Programa Embrapa de Melhoramento de Gado de Corte - Geneplus. Foram utilizadas informações de pesos e de escores visuais de conformação frigorífica obtidas à desmama e ao sobreano. Para a atribuição das notas de conformação frigorífica à desmama e ao sobreano (avaliação da harmonia entre desenvolvimento de musculatura, acabamento de gordura subcutânea e estrutura da carcaça), foi realizada, primeiramente, uma inspeção geral do lote de animais (grupo contemporâneo) que seria avaliado. Posteriormente, foram fornecidos escores individuais de modo comparativo entre os animais (escore relativo ao grupo contemporâneo no qual o animal se inseria), que variam de um a seis, sendo que o escore seis de conformação frigorífica representa a expressão mais desejável da característica. Para as análises, foram utilizadas 6.397 informações de peso e conformação frigorífica, obtidas à desmama e ao sobreano, referentes a animais de ambos os sexos e nascidos no período de 1995 a 2008.

A formação dos arquivos de dados e a análise de consistência foram feitas por meio dos programas Microsoft Acces (2003) e Statistical Analysis System (SAS, 2000). O peso à desmama foi padronizado para 240 dias, e o peso ao sobreano para 420 dias de idade, utilizando-se o ganho de peso médio diário entre pesagens consecutivas (interpolação). Foram descartados grupos contemporâneos contendo menos de cinco animais. Além dessa restrição, para peso à 
desmama e peso ao sobreano, foram retirados animais com observações com valores superiores ou inferiores a três desvios-padrão em relação à média. Os animais que possuíam mãe com idade menor do que 730 dias ou maior do que 8.030 dias também foram eliminados. Na Tab. 1 é apresentada a descrição estatística das observações das características estudadas.

Tabela 1. Estatística descritiva do peso e conformação frigorífica à desmama e ao sobreano

\begin{tabular}{lccccc} 
Característica & $\mathrm{N}$ & Média & DP & CV & GC \\
\hline PD & 6.397 & 196,16 & 30,57 & 15,58 & 344 \\
PS & 6.397 & 243,29 & 42,09 & 17,30 & 236 \\
CFD & 6.397 & 3,70 & 1,07 & 28,91 & 344 \\
CFS & 6.397 & 3,56 & 1,08 & 30,33 & 236 \\
\hline
\end{tabular}

$\mathrm{PD}=$ peso à desmama; $\mathrm{PS}=$ peso ao sobreano; $\mathrm{CFD}=$ conformação frigorífica à desmama; CFS = conformação frigorífica ao sobreano; $\mathrm{N}=$ número de observações por característica; $\mathrm{DP}=$ desvio-padrão; $\mathrm{CV}=$ coeficiente de variação; $\mathrm{GC}=$ número de grupos contemporâneos para a característica.

Os componentes de (co)variância foram estimados por intermédio do modelo animal empregando-se a metodologia REML (Restricted Maximum Likelihood - Máxima Verossimilhança Restrita), descrita por Patterson e Thompson (1971). A aplicação do REML foi feita por meio do programa REMLF90, desenvolvido por Misztal (2000), que utiliza o algoritmo de maximização da esperança (EM). O critério de convergência adotado foi o valor de $2 \log$ de verossimilhança igual ou menor que $1 \times 10^{-11}$.

Os efeitos fixos para peso e conformação frigorífica à desmama foram reunidos em grupos contemporâneos e definidos pelos fatores sexo, estação de nascimento (com duração de três meses: janeiro a março, abril a junho, julho a setembro e outubro a dezembro), ano de nascimento, fazenda, regime alimentar e data de avaliação. O mesmo critério foi adotado para peso e conformação frigorífica ao sobreano, admitindo-se o regime alimentar ao desmame, o regime alimentar ao sobreano e a data de avaliação ao sobreano.
O modelo multicaracterística utilizado na análise, em notação matricial, foi:

$$
y=X b+Z_{1} a+Z_{2} m+Z_{3} p e m+e,
$$

em que $y$ é o vetor de observações, $b$ é o vetor de efeitos fixos (grupo contemporâneo, idade da mãe à avaliação - efeitos linear e quadrático, idade do animal à avaliação para características de conformação frigorífica - efeito linear), $a$ é o vetor de efeitos aleatórios genéticos aditivos diretos, $m$ é o vetor aleatório de efeitos genéticos aditivos maternos, pem é o vetor aleatório de efeitos ambientais permanentes maternos e $e_{i}$ é o vetor de resíduos aleatórios. $X, Z_{1}, Z_{2}, Z_{3}$ são matrizes de incidência que relacionam os efeitos $b, a, m$ e pem ao vetor de observações.

Admitindo-se a distribuição normal conjunta dos vetores aleatórios, têm-se adicionalmente as seguintes pressuposições:

$$
\left[\begin{array}{c}
a \\
m \\
p e m \\
e
\end{array}\right] \sim N M V\left(\left[\begin{array}{c}
\phi \\
\phi \\
\phi \\
\phi
\end{array}\right],\left[\begin{array}{cccc}
A \sigma_{a}^{2} & A \sigma_{a m} & 0 & 0 \\
A \sigma_{a m} & A \sigma_{m}^{2} & 0 & 0 \\
0 & 0 & I \sigma_{p e m}^{2} & 0 \\
0 & 0 & 0 & I \sigma_{e}^{2}
\end{array}\right]\right),
$$

em que $\sigma_{a}^{2}$ é a variância genética aditiva direta, $\sigma_{m}^{2}$ é a variância genética aditiva materna, $\sigma_{a m}$ é a covariância genética aditiva direta e materna, $\sigma_{p e m}^{2}$ é a variância de ambiente permanente materno, $\sigma_{e}^{2}$ é a variância residual, $A$ é a matriz dos numeradores dos coeficientes de parentesco de Wright e $I$ é uma matriz identidade. 


\section{Wenceslau et al.}

\section{RESULTADOS E DISCUSSÃO}

Na Tab. 2, são apresentadas as estimativas dos componentes de (co)variância para as características estudadas.

A variância genética aditiva direta explicou maior porção da variância fenotípica comparada à variância genética aditiva materna e à variância de ambiente permanente materno para todas as características avaliadas. Também para todas as características foram estimadas covariâncias negativas entre o efeito genético aditivo direto e o efeito genético aditivo materno. Portanto, a seleção baseada no valor genético aditivo direto dessas características resultaria na redução do mérito genético aditivo materno. Resultados semelhantes foram observados por Barichello
(2007), ao estudar as características de peso e conformação frigorífica à desmama em animais da raça Canchim. As correlações genéticas entre o efeito genético aditivo direto e o efeito genético aditivo materno para as características avaliadas à desmama apresentaram valores de baixa magnitude. Porém, para as características avaliadas ao sobreano, a correlação genética entre esses efeitos foi de magnitude moderada, o que sugere que a escolha dos melhores animais, baseada no valor genético aditivo direto, resultaria em seleção inversa dos valores genéticos aditivos maternos.

$\mathrm{Na}$ Tab. 3, são apresentadas as estimativas de herdabilidade e de correlação genética para as características estudadas.

Tabela 2. Componentes de (co)variância do peso à desmama (PD), peso ao sobreano (PS), conformação frigorífica à desmama (CFD) e conformação frigorífica ao sobreano (CFS)

\begin{tabular}{lcccccc} 
& $\sigma_{a}^{2}$ & $\sigma_{m}^{2}$ & $\sigma_{p e m}^{2}$ & $\sigma_{e}^{2}$ & $\sigma_{a m}$ & $r_{a m}$ \\
\hline PD & 97,77 & 37,76 & 58,00 & 258,10 & $-2,33$ & -0.03 \\
PS & 221,10 & 33,65 & 50,42 & 408,30 & $-44,46$ & $-0,51$ \\
CFD & 0,1066 & 0,0678 & 0,0632 & 0,5972 & $-0,0249$ & $-0,29$ \\
CFS & 0,2024 & 0,0562 & 0,0352 & 0,5669 & $-0,0559$ & $-0,52$ \\
\hline
\end{tabular}

$\sigma_{a}^{2}=$ variância genética aditiva direta; $\sigma_{m}^{2}=$ variância genética aditiva materna; $\sigma_{p e m}^{2}=$ variância de ambiente permanente materno; $\sigma_{e}^{2}=$ variância residual; $\sigma_{a m}=$ covariância entre o efeito genético aditivo direto e o efeito genético aditivo materno; $r_{a m}=$ correlação entre o efeito genético aditivo direto e o efeito genético aditivo materno.

Tabela 3. Estimativas de herdabilidade (diagonal) e correlação genética (acima da diagonal) para peso e conformação frigorífica, à desmama e ao sobreano

\begin{tabular}{lcccc}
\hline Característica & PD & PS & CFD & CFS \\
\hline PD & 0,22 & 0,92 & 0,75 & 0,61 \\
PS & & 0,29 & 0,81 & 0,80 \\
CFD & & 0,13 & 0,89 \\
CFS & & & & 0,25 \\
\hline
\end{tabular}

$\mathrm{PD}=$ peso à desmama, $\mathrm{PS}=$ peso ao sobreano, $\mathrm{CFD}=$ conformação frigorífica à desmama; CFS = conformação frigorífica ao sobreano.

Os valores de herdabilidade do peso à desmama e do peso ao sobreano obtidos no presente estudo indicam a possibilidade de progresso genético ao se utilizarem estas características no estabelecimento do critério de seleção. A herdabilidade estimada do peso à desmama $(0,22)$ está em conformidade com os valores publicados na literatura. Nobre et al. (2003) relataram herdabilidade do peso à desmama com valores variando de 0,13 a 0,20 , ao compararem o modelo multicaracterística e de regressão aleatória utilizando dados de animais Nelore. Koury Filho (2005) e Yokoo (2005) estimaram herdabilidade de 0,34 para a característica, também, ao estudarem animais da raça Nelore, enquanto Gressler et al. (2005) obtiveram estimativa mais alta, com valor de 0,48. A estimativa de herdabilidade do peso ao sobreano 
foi de magnitude moderada $(0,29)$ e está de acordo com os estudos realizados na raça Nelore por Nobre et al. (2003), Costa et al. (2004), Koury Filho (2005) e Yokoo (2005), que relataram valores de herdabilidade do peso ao sobreano que variaram de 0,17 a 0,24 no primeiro trabalho e foram de $0,21,0,37$ e 0,34 nos demais trabalhos, respectivamente.

A estimativa de herdabilidade da conformação frigorífica à desmama foi de 0,13 , portanto de baixa magnitude. Barichello (2007) relatou herdabilidade para a característica de conformação frigorífica à desmama, que variou de 0,17 a 0,27, ao analisar quatro diferentes modelos de avaliação para animais da raça Canchim. Ao avaliar escores visuais de conformação, precocidade e musculosidade em bovinos Nelore à desmama, Koury Filho (2005) observou herdabilidades de 0,13, 0,25 e 0,23, respectivamente, valores de menor magnitude do que os apresentados por Carneiro (2007), que obteve estimativas de $0,28,0,33$ e 0,36 para essas características. Cardoso et al. (2001) relataram valores de $0,18,0,19$ e 0,19 , respectivamente, para a herdabilidade de conformação, precocidade e musculatura em animais da raça Angus.

A estimativa de herdabilidade da conformação frigorífica ao sobreano foi de 0,25. Apesar de não terem sido encontrados outros trabalhos em que a conformação frigorífica ao sobreano foi avaliada, a estimativa apresentada neste estudo é similar às observadas por outros autores para características de carcaça avaliadas por escores visuais em idades próximas a essa. Van Melis et al. (2003) relataram herdabilidades de 0,22, 0,21 e 0,22 para as características de conformação, precocidade e musculatura em animais Nelore de 18 meses, ao utilizarem diferentes metodologias de estimação de componentes de (co)variância. Faria et al. (2009) observaram estimativas de herdabilidade de 0,38, 0,14 e 0,07 para as características de musculatura, estrutura física e conformação, ao avaliarem bovinos da raça Nelore aos 15 meses de idade. Estimativas de $0,19,0,25$ e 0,26 foram apresentadas por Cardoso et al. (2004) para as características de conformação, precocidade e musculosidade, ao analisarem dados de animais da raça Angus no período de sobreano. Koury Filho (2005) obteve estimativas de herdabilidade iguais a 0,24, 0,63 e 0,48 para estrutura corporal, precocidade e musculosidade, ao avaliar dados de animais Nelore ao sobreano, respectivamente. Os resultados, segundo o autor, sugerem grande variabilidade genética entre os animais, porém foram obtidos a partir de arquivo de dados com pequeno número de observações, feitas em um único ano e por um único avaliador. Koury Filho (2005) ainda conclui que a opção de se utilizarem escores visuais em programas de melhoramento genético se dá pela avaliação rápida de grande número de animais. Para reduzir, contudo, o efeito advindo dos avaliadores, é necessário que estes sejam treinados e que a metodologia adotada seja de simples aplicação e entendimento.

A correlação genética estimada entre os pesos à desmama e ao sobreano de 0,92 sugere que animais selecionados para a segunda característica também seriam escolhidos quando a seleção fosse baseada na primeira. Este resultado é semelhante ao observado por Mercadante et al. (2007), que apresentaram valor de 0,96 para correlação genética entre o peso à desmama e o peso ao sobreano.

As estimativas de correlações genéticas entre as características de desenvolvimento ponderal peso à desmama e ao sobreano - e as características de carcaça - conformação frigorífica à desmama e ao sobreano - foram positivas e de alta magnitude e variaram de 0,61 a 0,81 . Resultados semelhantes foram descritos por Koury Filho (2005), que, ao estimar a correlação genética entre o peso à desmama e as características de conformação, precocidade e musculatura medidas na mesma idade, obteve $0,71,0,42$ e 0,43 , respectivamente. Correlações genéticas estimadas para os mesmos pares de características, porém mensuradas ao sobreano, foram iguais a 0,83, 0,59 e 0,58, respectivamente. Cardoso et al. (2001) observaram valores de 0,86, 0,71 e 0,82, respectivamente, para as correlações genéticas entre o ganho de peso ajustado para 205 dias de idade e as características de conformação, precocidade e musculatura. Barichello (2007) estimou a correlação genética entre o peso à desmama e a conformação frigorífica à desmama de animais Canchim em 0,61.

As correlações genéticas estimadas sugerem que as características de peso e de conformação 
frigorífica são influenciadas, pelo menos em parte, por genes em comum. Pode-se inferir, portanto, que ocorrerá mudança genética simultânea e de mesma direção em uma característica quando a seleção for baseada na outra. Deve-se, porém, aceitar com cautela as estimativas de correlação genética entre as características de peso e de conformação frigorífica, pois os avaliadores podem ser influenciados pelo peso do animal ao estabelecerem a nota para a característica de conformação frigorífica. Caso essa influência exista, a avaliação genética dos animais e a interpretação dos resultados gerados podem ser prejudicadas.

A correlação genética de 0,89 , estimada entre a conformação frigorífica à desmama e ao sobreano, foi semelhante às observadas por Cardoso et al. (2004), que relataram valores de $0,99,0,93$ e 0,90 , respectivamente, para correlação genética entre as características de conformação, precocidade e musculatura à desmama e as mesmas características ao sobreano. Koury Filho (2005) também observou resultados similares para a estimativa da correlação genética para conformação, precocidade e musculosidade à desmama e ao sobreano, com valores, respectivamente, de 0,80 , 0,86 e 0,86 . A estimativa de correlação genética obtida entre a conformação frigorífica à desmama e a conformação frigorífica ao sobreano sugere que a seleção para essas características pode ser realizada em menor idade, sem prejuízos na escolha dos animais para a reprodução. Assim, evitar-se-iam gastos com a criação de animais que não seriam futuramente selecionados. Segundo Cardoso et al. (2004), os escores visuais podem ser avaliados somente em uma fase da vida do animal, dando-se preferência ao momento da desmama, evitando-se, desse modo, a perda de informação por pré-seleção. Porém, deve-se aceitar essa sugestão com cautela no presente estudo, pois as herdabilidades das características avaliadas à desmama foram menores que aquelas avaliadas ao sobreano.

\section{CONCLUSÕES}

As herdabilidades das características de peso e de conformação frigorífica à desmama e ao sobreano, de baixa a moderada magnitude, sugerem que ganhos genéticos podem ser obtidos pela seleção para estas características. As correlações genéticas positivas de média a alta magnitude entre as características de peso e de conformação frigorífica nas diferentes idades sugerem que a seleção para uma delas gera, como resposta correlacionada, ganho genético na outra característica. Em um programa de seleção para incrementar características de peso e conformação frigorífica, os animais poderiam ser avaliados em apenas um período da vida, em razão das altas correlações genéticas entre essas características avaliadas nas diferentes idades.

\section{REFERENCIAS}

BARICHELLO, F. Estimativas de parâmetros genéticos para escores de avaliação visual, peso e perímetro escrotal à desmama de bovinos da raça Canchim. 2007. 81f. Dissertação (Mestrado em Genética e Melhoramento Animal) Faculdade de Ciências Agrárias e Veterinárias, Universidade Estadual Paulista, Jaboticabal, SP.

CARDOSO, F.F.; CARDELLINO, R.A.; CAMPOS, L.T. Componentes de (co)variância e parâmetros genéticos de caracteres pós-desmama em bovinos da raça Angus. Rev. Bras. Zootec., v.33, p.313-319, 2004.

CARDOSO, F.F.; CARDELLINO, R.A.; CAMPOS, L.T. Componentes de (co)variância e parâmetros genéticos para caracteres produtivos à desmama de bezerros Angus criados no estado do Rio Grande do Sul. Rev. Bras. Zootec., v.30, p.41-48, 2001.

CARNEIRO, R.L.R. Estimativas de parâmetros genéticos de escore de temperamento e de características de crescimento e de carcaça em animais da raça Nelore. 2007. 57f. Dissertação (Mestrado em Genética e Melhoramento Animal) - Faculdade de Ciências Agrárias e Veterinárias, Universidade Estadual Paulista, Jaboticabal, SP.

COSTA, B.C.; LAUREANO, M.M.M.; FORNI, S. et al. Estimativas de parâmetros genéticos para as características perímetro escrotal, peso ao sobreano e idade ao primeiro parto em um rebanho da raça Nelore. In: SIMPÓSIO DA SOCIEDADE BRASILEIRA DE MELHORAMENTO ANIMAL, 5., 2004, Pirassununga, SP. Anais... Pirassununga: SBMA, 2004. 
FARIA, C.U.; MAGNABOSCO, C.U.; ALBUQUERQUE, L.G. et al. Utilização de escores visuais de características morfológicas de bovinos Nelore como ferramenta para o melhoramento genético animal. 1.ed. Planaltina: EMBRAPA Cerrados, 2007. 40 p.

FARIA, C.U.; MAGNABOSCO, C.U.; ALBUQUERQUE, L.G. et al. Análise genética de escores visuais em bovinos da raça Nelore, na desmama até a maturidade. In: REUNIÃO ANUAL DA SOCIEDADE BRASILEIRA DE ZOOTECNIA, 46., 2009, Maringá, PR. Anais... Maringá: SBZ, 2009.

GRESSLER, M.G.M.; PEREIRA, J.C.C.; BERGMANN, J.A.G. et al. Aspectos genéticos do peso à desmama e de algumas características reprodutivas de fêmeas Nelore. Arq. Bras. Med. Vet. Zootec., v.57, p.533-538, 2005.

JOSAHKIAN, L.A.; MACHADO, C.H.C.; KOURY FILHO, W. Programa de melhoramento genético das raças zebuínas - Manual de Operação. Uberaba, MG: ABCZ, 2003. 98 p.

KIPPERT, C.J.; RORATO, P.R.N.; CAMPOS, L.T. et al. Efeito de fatores ambientais sobre escores de avaliação visual à desmama e estimativa de parâmetros genéticos, para bezerros da raça Charolês. Cienc. Rural, v.36, p.579-585, 2006.

KOURY FILHO, W. Escores visuais e suas relações com características de crescimento em bovinos de corte. 2005. 80f. Tese (Doutorado em Zootecnia) - Faculdade de Ciências Agrárias e Veterinárias, Universidade Estadual Paulista, Jaboticabal, SP.

KOURY FILHO, W. Análise genética de escores de avaliações visuais e suas respectivas relações com desempenho ponderal na raça Nelore. 2001. 82f. Dissertação (Mestrado) - Faculdade de Zootecnia e Engenharia de Alimentos, Universidade de São Paulo.

MAY, S.G.; MIES, W.L.; EDWARDS, J.W. et al. Effect of frame size, muscle score, and external fatness on live and carcass value of beef cattle. J. Anim. Sci., v.70. p.3311-3316, 1992.
MERCADANTE, M.E.; RAZOOK, A.G.; FIGUEIREDO, L.A. et al. Análise genética multivariada e tendências genéticas de características de crescimento em rebanhos experimentais da raça Nelore. In: REUNIÓN DE LA ASOCIACIÓN LATINOAMERICANA DE PRODUCCIÓN ANIMAL, 20,, 2000, Cusco, Anais... Cusco: ALPA, 2007.

MICROSOFT CORPORATION. Microsoft Access 2003 software, 2003.

MISZTAL, I. REMLF90 Manual. 2000. Disponível em:

$<$ http://nce.ads.uga.edu/ ignacy/newprograms.ht ml/>. Acessado em: 20 dez. 2009.

NOBRE, P.R.C.; MISZTAL, I.; TSURUTA, S. et al. Genetic evaluation of growth in Nellore cattle by multiple-trait and random regression models. J. Anim. Sci., v.81, p.927-932, 2003.

PATTERSON, H.D.; THOMPSON, R. Recovery of inter-block information when block size are unequal. Biometrics, v.58, p.545-554, 1971.

SAS INSTITUTE. SAS/STAT Software: changes and enhancement through release 8.2. Cary, 2000.

VAN MELIS, M.H.; ELER, J.P.; SILVA, J.A.V. et al. Estimação de parâmetros genéticos em bovinos de corte utilizando os métodos de máxima verossimilhança restrita e R. Rev. Bras. Zootec., v.32, p.1624-1632, 2003.

YOKOO, M.J. Estimativas de efeitos genéticos $e$ ambientais para características de carcaça medidas pelo ultrassom em bovinos da raça Nelore. 2005. 89f. Dissertação (Mestrado em Genética e Melhoramento Animal) - Faculdade de Ciências Agrárias e Veterinárias, Universidade Estadual Paulista, Jaboticabal, SP.

YOKOO, M.J.; WERNECK, J.N.; PEREIRA, M.C. et al. Correlações genéticas entre escores visuais e características de carcaça medidas por ultrassom em bovinos de corte. Pesq. Agropec. Bras., v.44, p.197-202, 2009. 